\title{
Characterization of Compositional Gradient Structure of Polymeric Materials by FTIR Technology
}

\author{
Alata Hexig and Bayar Hexig* \\ Department of Biomolecular Engineering, \\ Graduate School of Bioscience and Biotechnology, \\ Tokyo Institute of Technology, Nagatsuta-cho, \\ Midori-ku, Yokohama \\ Japan
}

\section{Introduction}

Biomimetic and bioinspired optimal structures combining bioresorbable, bioactive and other advanced properties are expected for the next generation of biomaterials (Bruck et al., 2002, Hench et al., 2002, Akaike et al., 2005). Inspired by nature, to reveal the relationship between structure and functionality of biological materials has been emphasized in the biomaterials research field. In nature, gradient biological structures exist most commonly, such as the structure of bamboo (Amada et al., 1997), shells, teeth, bones, tendon and extracellular matrix (ECM) (Suresh et al., 2001). Man-made functionally gradient materials (FGMs) have been developed for combining irreconcilable properties within a single material and have been widely incorporated in metal/ceramic and organic/inorganic material fields for increasing the structural complexity and combining different functionality (Suganuma et al., 1983, Ishikawa et al., 2002, Czubarow et al., 1997). FGMs are spatial composites within which the composition or structure and thus the functions of the materials continuously or step-wisely vary along the specific coordinates. Examples of the structural change include those in crystal structure and orientation, porosity, particle size and so on.

The concept of FGMs first originated in Japan in 1984-1985 in the spacecraft project (Kawasaki et al., 1987). FGMs are developed to give two conflicting properties such as good thermal conductivity and good thermal resistance into one material. In general, we see uniformed functions and properties within the materials we use. However, in FGMs we see different functions between one part and the other of them. In a metal-ceramic FGM, the metal-rich side is placed in the region where mechanical performance, such as toughness, needs to be stronger; and the ceramic-rich side, which has better thermal resistance, is exposed to high temperatures, or placed in the region where there is a potentially severe temperature variation (Dao et al., 1997). In FGMs, the properties change gradually with position due to the spatial gradients in composition, density, microstructural arrangement or atomic-order, which

${ }^{*}$ Corresponding Author 
contribute to distribute thermal stresses, to reduce mechanical stress, and to improve interfacial bonding between dissimilar materials. This kind of materials also provides other functional properties depending on their constituents of composites, such as gradient optical polymers and multifocal lenses (Zuccarello et al., 2002, Kryszewski et al., 1998, Ma et al., 2002).

Recently, there have been many efforts to develop polymeric FGMs with unique properties and advanced functions that are inaccessible in conventional uniform systems (Agari et al., 1996, Kano et al., 1997, Xie et al., 1998,). In particular, compositional gradient biodegradable polymeric materials have many potential applications for biomedical devices and tissue engineering, and we consider they may lead to a wide range of new generation of biomedical materials. Polymeric FGMs have great potential to be used in various fields such as separation membrane, adhesive, and biomedical materials including artificial skin, artificial bone and teeth, drug delivery system, and so on. However, the difference in structure, functional group, miscibility, solvent, and thermal treatment, induced a large complexity for designing, preparing, confirming, and characterizing polymeric FGMs. Many preparation approaches have been developed to generate a polymeric functionally gradient structure during homogenization or segregation processes. Despite these efforts made recently to generate polymeric FGMs, characterization of their gradient structure, physicochemical properties and elucidation of formation mechanisms still remain to be explored. In this chapter, we will mainly discuss the confirming methods of compositional gradient structure of polymeric FGMs using FT-IR technology (such as ATR-FTIR, Mapping measurement of FTIR, and PAS-FTIR). FT-IR has been proven to be a powerful technique for characterizing the compositional differences of gradient film materials from surface to inside, and also on cross section. In our previous studies, four different compositional gradient polymeric materials have been prepared in miscible or immiscible blend systems, and in all these works, FT-IR has been applied as a main method for confirming the compositional gradient structure of the prepared materials (Hexig et al., 2005, 2010).

\section{ATR-FTIR for confirming the compositional difference between two surfaces of polymeric FGM film}

The consentaneous confirming standard for polymeric materials with gradient structure has not been established yet. In general, ATR-FTIR can give the information about chemical composition in the range from the top surface into a few $\mu \mathrm{m}$ deep. We have been utilizing ATRFTIR for confirming the compositional difference between two surfaces of polymeric FGMs.

We successfully prepared a novel polymeric material with compositional gradient in a binary miscible biodegradable polymer blend system, that is, poly(butylene succinate)(PBS)/ poly(ethylene oxide)(PEO) blend through controlling interdiffusion process at a temperature above the melting points of both components. The semicrystalline polymer PEO has attracted much attention and has been extensively investigated both experimentally and theoretically during recent decades (Allen et al., 1999). PEO is biocompatible, biodegradable, and water-soluble polymer (Dormidontova et al., 2002). These specific features of PEO make it applicable for drug delivery purposes, and it also has potential for other biomedical applications. PEO is miscible with several amorphous polymers through hydrogen bonding interaction (Miyoshi et al., 1996), and is also miscible with crystalline polymers, such as, poly(ethylene succinate)(PES) (Chen et al., 2000), and poly(3-hydroxypropionate) (PHP) (Na et al., 2002), while it is partly miscible or immiscible 
with bacterial (PHB) (He et al., 2000). Poly(1,4-butylene succinate)(PBS) is a biodegradable aliphatic semi-crystalline polymer and flexible thermoplastic polyester (Uesaka et al., 2000). The miscibility and crystallization behavior in homogenous blends of PEO/PBS have been investigated by DSC and optical microscopy. PEO and PBS were found to be miscible in the amorphous phase (Qiu et al., 2003).

\subsection{Sample preparation and creation of gradient film}

The films of PBS, PEO and the binary blend of PBS/PEO were prepared by solution casting method. Pure PBS and PEO films with thickness of $200 \pm 10 \mu \mathrm{m}$ were laminated together under pressure of $5 \mathrm{Mpa}$ to obtain the bilayered film, and then used for preparation of gradient film. The laminated PBS/PEO film was annealed at $140{ }^{\circ} \mathrm{C}$ for 24 hours in an oven in the vacuum condition. By this way, we could generate a continuous gradient structure in the thickness direction, which is difficult to achieve by a conventional stepped multi-layer process.

\subsection{Attenuated Total Reflectance Fourier Transform Infrared (ATR/FT-IR) spectroscopy}

ATR-FTIR spectra were recorded on a AIM-8800 FT-IR spectrometer ( Shimazu Co.Ltd. Japan) equipped with a Diamond EX'Press in order to analyze the chemical composition of the surfaces. The sum of 64 scans with a resolution of $4 \mathrm{~cm}^{-1}$ was used to obtain the spectra.

\subsection{Results of ATR-FTIR measurements}

Figure 1 shows the ATR-FTIR spectra of the film surface of pure PBS, PEO and 50/50 (wt $\% / w t \%$ ) PBS/PEO blend. The peak centered at wavenumber $1724 \mathrm{~cm}^{-1}$ corresponding to

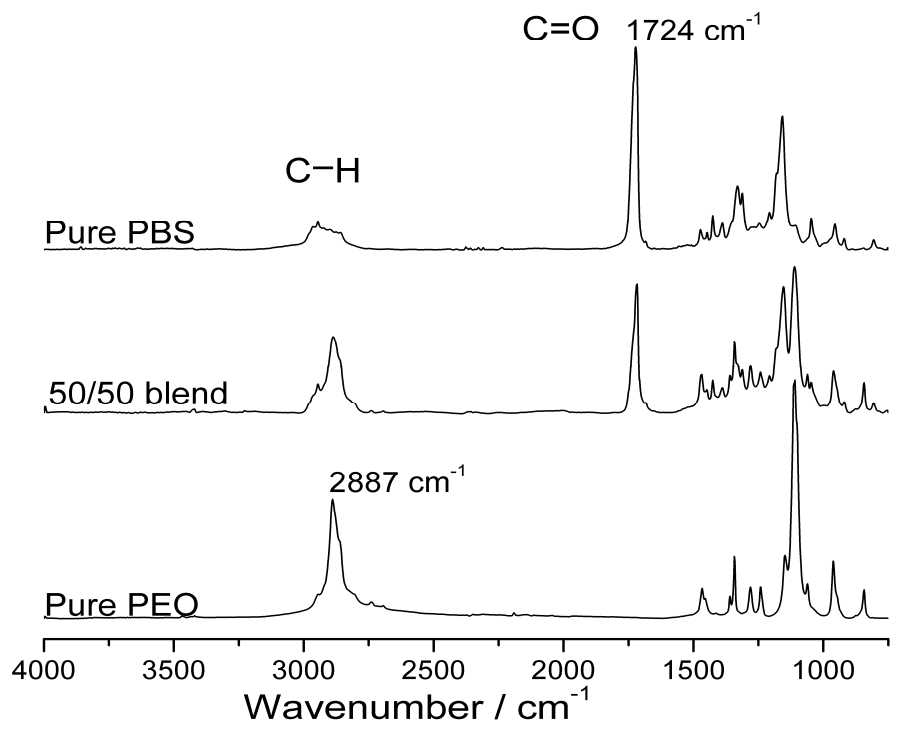

Fig. 1. ATR-FTIR spectra of pure PBS, PEO, and 50/50(wt\%/wt\%) PBS/PEO binary blend observed at room temperature. 
the carbonyl vibration region of PBS and that at $2887 \mathrm{~cm}^{-1}$ corresponding to the C-H stretching region of PEO were detected for the pure PBS and PEO films, respectively, at room temperature. Both of these characteristic peaks also appeared in the 50/50(wt\%/wt\%)PBS/PEO blend film. There are also some bands in the C-H stretching region in the spectrum of pure PBS, but they are very weak and broad. Therefore, the two peaks at $1724 \mathrm{~cm}^{-1}$ and $2887 \mathrm{~cm}^{-1}$ can be used to analyze qualitatively the contents of the PBS and the PEO components at the arbitrary position in the compositional gradient film. The difference of the chemical composition between the two surfaces of the compositional gradient film was examined by means of ATR-FTIR, as shown in Figure 2. It shows that the PBS has notably diffused to the PEO side while a comparatively small fraction of PEO diffused to the PBS side, implying that the composition varies from one side to the other side of the film.

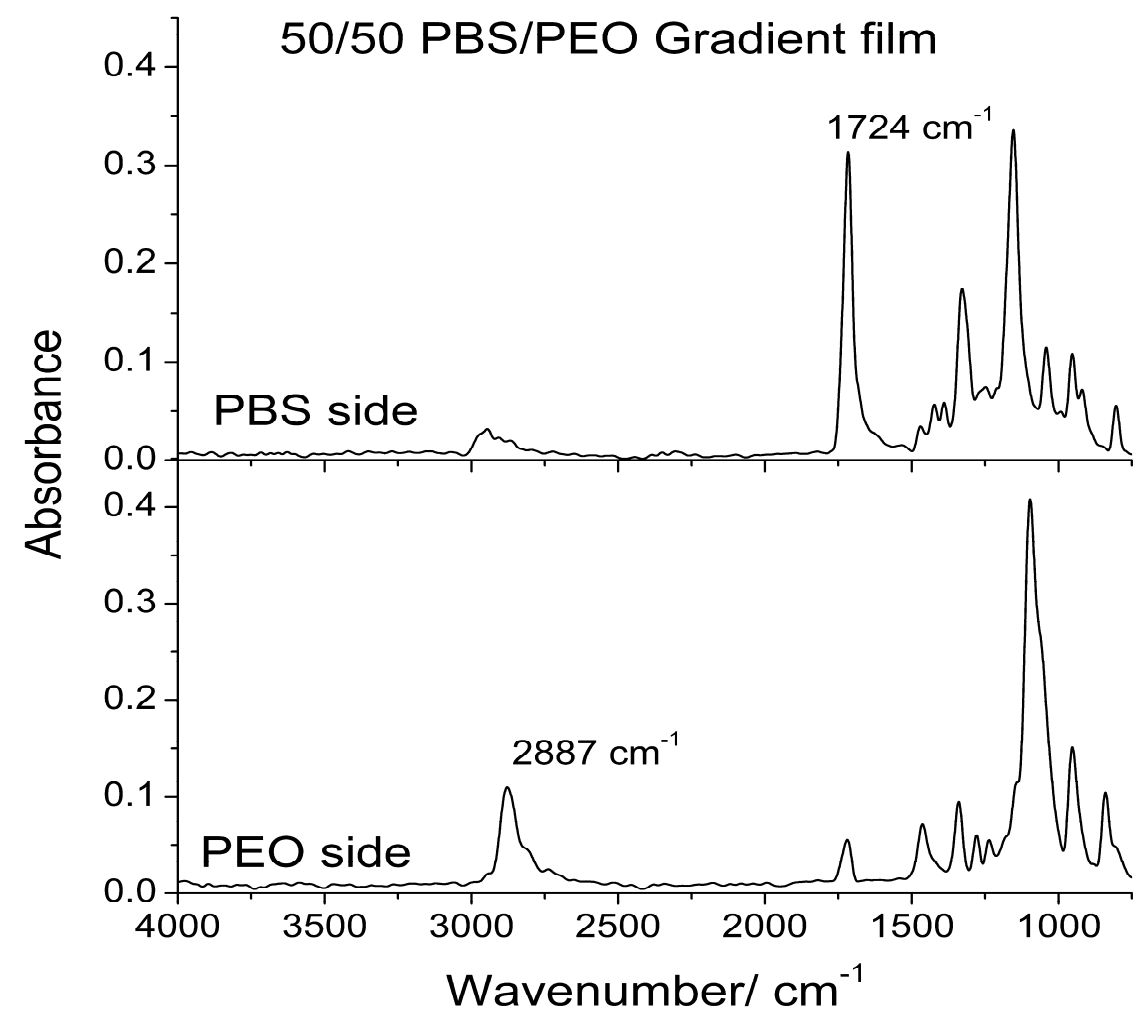

Fig. 2. ATR-FTIR spectra on both surfaces of the compositional gradient film observed at room temperature.

\section{FT-IR mapping measurements for characterizing the compositional change along the thickness direction of polymeric FGMs}

The fact that only a limited amount of miscible biodegradable polymer pairs are available constrains preparation of biodegradable polymeric gradient materials with high quality and 
a wide range of applications. In the case of immiscible polymer system, the contributions from favorable intermolecular interactions are not enough to overwhelm the unfavorable contribution arising from the solubility parameters (Coleman et al., 1991). The addition of low molecular-weight agent is a well-known way to modify polymeric material properties and even improve the miscibility in case of immiscible polymer blends.

Our interest is to develop a new strategy for creation of functionally gradient polymeric composite materials in immiscible polymer blend system utilizing the miscibilization effect of low molecular-weight agent. Two kinds of commercially available biodegradable polymers, namely, a random copolyester, poly(butylene adipate-co- $44 \mathrm{~mol} \%$ butylenes terephthalate) $[\mathrm{P}(\mathrm{BA}-\mathrm{co}-\mathrm{BT})]$ and water-soluble poly(ethylene-oxide)(PEO) are chosen for this purpose, because $\mathrm{P}(\mathrm{BA}-\mathrm{co}-\mathrm{BT})$ and $\mathrm{PEO}$ are immiscible over the whole range of blend composition, but two components become miscible in the presence of optimum amount of low molecular-weight component 4,4'-thiodiphenol (TDP) as reported in our previous study (Hexig et al., 2004). It has been found that a suitable content of TDP has the ability to improve the miscibility between $\mathrm{P}(\mathrm{BA}-\mathrm{CO}-\mathrm{BT})$ and $\mathrm{PEO}$ through intermolecular hydrogen bonding interaction, as revealed by DSC and FT-IR measurements (Figure 3). In this work, we demonstrate the generation of compositional gradient phase structure in the immiscible $\mathrm{P}(\mathrm{BA}-\mathrm{co}-\mathrm{BT}) / \mathrm{PEO}$ system through improving the miscibility between two components by the formation of TDP-mediated hydrogen bonds. The formation of compositional gradient was confirmed by FT-IR mapping measurement.

\subsection{Sample preparation and creation of gradient film}

The films of pure $\mathrm{P}(\mathrm{BA}-\mathrm{co}-\mathrm{BT})$, pure $\mathrm{PEO}$, binary blends $\mathrm{P}(\mathrm{BA}-\mathrm{co}-\mathrm{BT}) / \mathrm{TDP}(92 / 8 \mathrm{wt} \% / \mathrm{wt} \%)$ and PEO/TDP (92/8 $\mathrm{wt} \% / \mathrm{wt} \%)$, and the ternary blend of $\mathrm{P}(\mathrm{BA}-\mathrm{co}-\mathrm{BT}) / \mathrm{PEO} / \mathrm{TDP}$ containing a constant composition( $8 \mathrm{wt} \%)$ of TDP with various $\mathrm{P}(\mathrm{BA}-\mathrm{BO}-\mathrm{BT}) / \mathrm{PEO}$ ratios were prepared by conventional solution casting method. $5 \mathrm{wt} \%$ Polymer solution in 1,4dioxane was stirred for $6-8 \mathrm{~h}$ and cast on a Teflon dish. The solvent was allowed to evaporate slowly for 1 day at ambient temperature. The resulted films were then dried in a vacuum oven at $50{ }^{\circ} \mathrm{C}$ for 2 days to remove residual solvent and subsequently compression molded between Teflon sheets for $3 \mathrm{~min}$ at $160{ }^{\circ} \mathrm{C}$ under pressure of $5 \mathrm{MPa}$ by using laboratory press (Mini Test Press-10, Toyoseiki Co., Japan).

An in situ formation process that we used to create the gradient films is illustrated schematically in Figure 4. The low molecular weight TDP is expected to enhance the miscibility and induce the interdiffution process. Firstly, the films of $\mathrm{P}(\mathrm{BA}-\mathrm{co}-\mathrm{BT}) / \mathrm{TDP}(92 / 8$ $w t \% / w t \%)$ and PEO/TDP (92/8 wt $\% / w t \%)$ with thickness of $200 \pm 10 \mu \mathrm{m}$ were laminated together under pressure of $5 \mathrm{Mpa}$ at room temperature to obtain a bilayered film, and then the laminated film was annealed at $140{ }^{\circ} \mathrm{C}$ in a vacuum oven to generate a gradient structure. In order to investigate the effect of gravity on the interdiffusion process, two laminated films were annealed in the same time, the one consists of $\mathrm{P}(\mathrm{BA}-\mathrm{co}-\mathrm{BT}) / \mathrm{TDP}(92 / 8$ $\mathrm{wt} \% / \mathrm{wt} \%)$ and $\mathrm{PEO} / \mathrm{TDP}(92 / 8 \mathrm{wt} \% / \mathrm{wt} \%)$ at the top and the bottom side, respectively, and the other one has the arrangement reverse to the first one. During the annealing process, the gradient structure of the resulted films was analyzed for several times and the best gradient phase in the whole thickness range was obtained after 12 hours annealing for both the films. The same process was also performed for the laminated film of $\mathrm{P}(\mathrm{BA}-\mathrm{co}-\mathrm{BT}) / \mathrm{PEO}$ without adding TDP. 

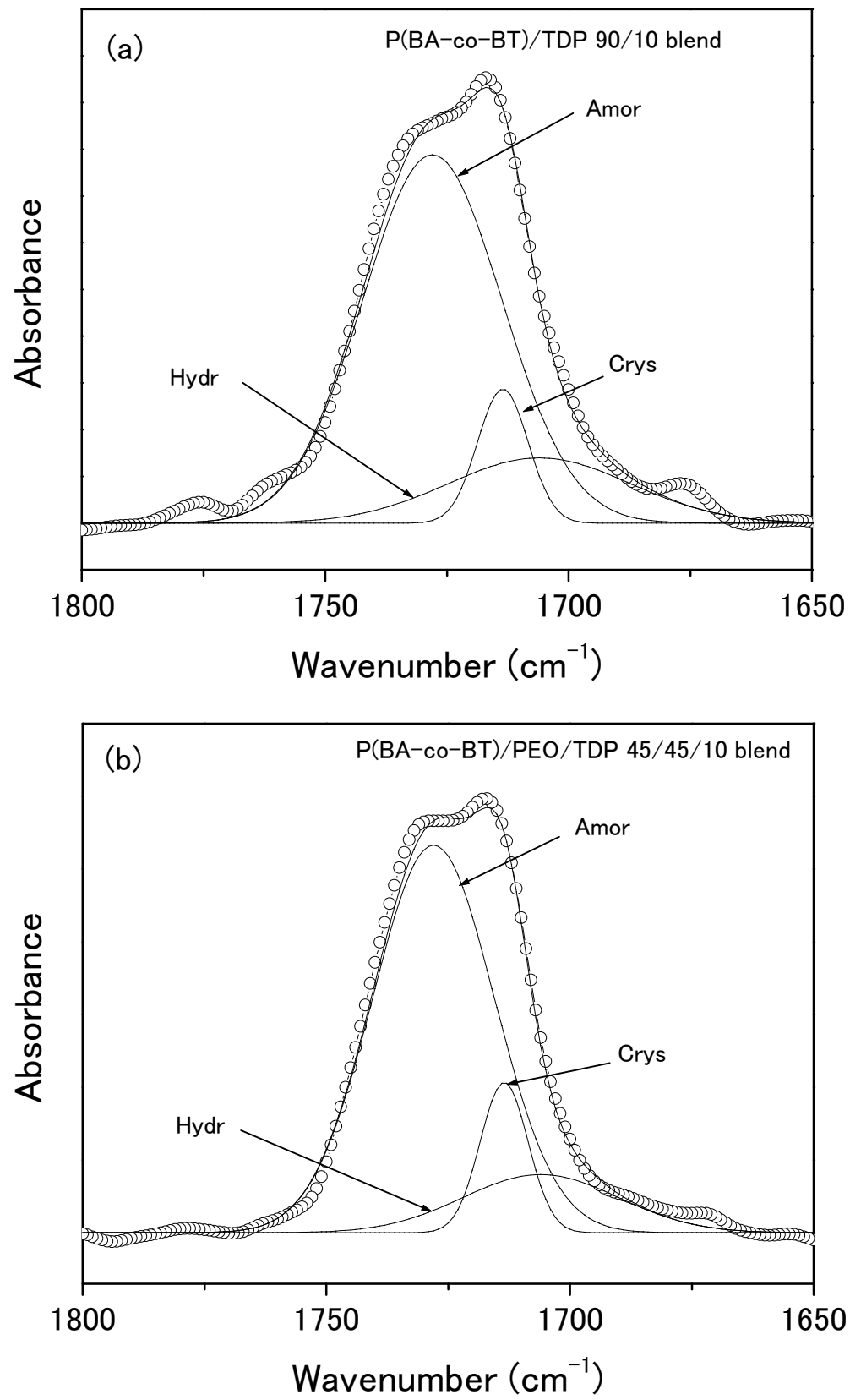

Fig. 3. Infrared spectra in the carbonyl stretching region for binary $\mathrm{P}(\mathrm{BA}-\mathrm{co}-\mathrm{BT}) / \mathrm{TDP}=90 / 10$ blend (a) and ternary $\mathrm{P}(\mathrm{BA}-\mathrm{co}-\mathrm{BT}) / \mathrm{PEO} / \mathrm{TDP}=45 / 45 / 10$ blend $(\mathrm{b})$ resolved by curve-fitting program; Amor.: amorphous component; Crys.: crystalline component; Hydr.: hydrogenbonded component; Fitt.: cunve-fitted; Exp.: experimental spectrum. 


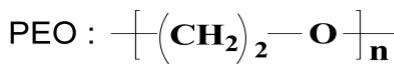<smiles>Oc1ccc(Sc2ccc(O)cc2)cc1</smiles>

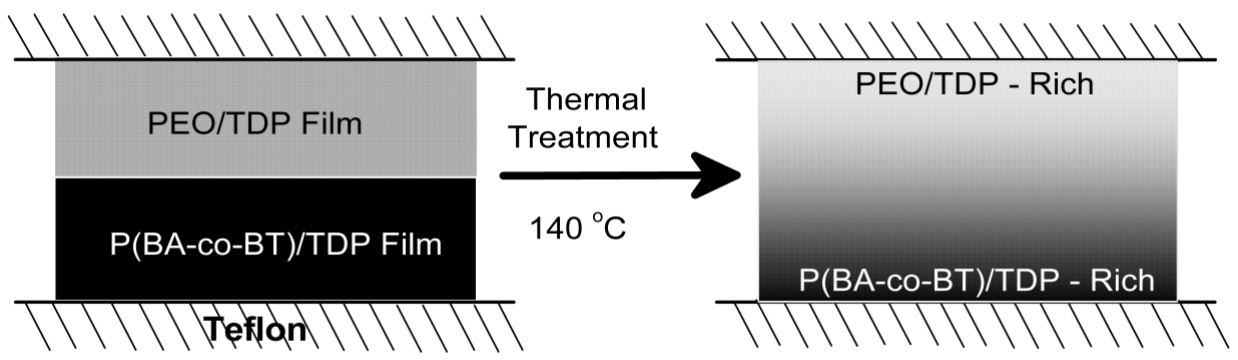

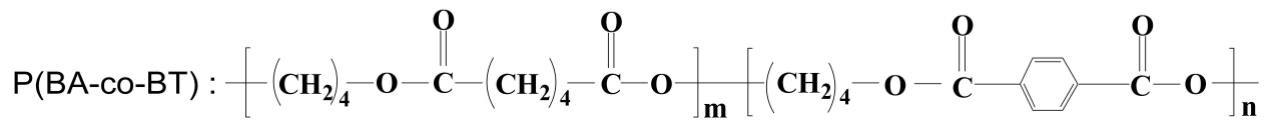

Fig. 4. Schematic illustration of the formation of P(BA-co-BT)/PEO/TDP compositional gradient film.

\subsection{FT-IR microscopy and mapping measurements}

The films of polymer blends used for the measurements of FT-IR were prepared by casting the polymer solution on the surface of a silicon wafer and dried under vacuum condition for 2 days. The film used in this study was thin enough to obey the Lambert-Beer law $(<0.6$ absorbance units). FT-IR spectra were recorded on a Perkin-Elmer Spectrum 2000 spectrometer using a minimum of 64 co-added scans at a resolution of $4 \mathrm{~cm}^{-1}$. Nitrogen was used to purge $\mathrm{CO}_{2}$ and gaseous water in the detector and sample compartments prior to and during the scans.

The sample for FT-IR mapping measurement of the film cross-section was prepared by slicing the film with microtome. FT-IR mapping measurements of the compositional gradient films were carried out by using a AIM-8800 FT-IR microscope (Shimazu Co.Ltd. Japan) equipped with a Diamond EX'Press. A square aperture of $30 \times 30 \mu \mathrm{m}$ was set on one side of the cross section and the aperture is automatically movable under a setting program. The $30 \times 30 \mu \mathrm{m}$ square aperture was displaced 50 times by a step of $10 \mu \mathrm{m}$. The sum of 64 scans with a resolution $4 \mathrm{~cm}^{-1}$ was averaged at each step. The spectra were then accumulated together to make a mapping mode spectrum.

\subsection{Results}

Figure 5 shows the FT-IR spectra of pure TDP, pure PEO, pure $\mathrm{P}(\mathrm{BA}-\mathrm{co}-\mathrm{BT})$, and their blends of $\mathrm{P}(\mathrm{BA}-\mathrm{co}-\mathrm{BT}) / \mathrm{TDP} 92 / 8(\mathrm{wt} \% / \mathrm{wt} \%), \mathrm{PEO} / \mathrm{TDP} 92 / 8(\mathrm{wt} \% / \mathrm{wt} \%)$, and P(BA-co$\mathrm{BT}) / \mathrm{PEO} / \mathrm{TDP} 46 / 46 / 8(\mathrm{wt} \% / \mathrm{wt} \% \mathrm{wt} \%$ ). The peaks centered at wavenumber $1488 \mathrm{~cm}-1$, $1596 \mathrm{~cm}^{-1}$ and $1612 \mathrm{~cm}^{-1}$ corresponding to the $\mathrm{C}=\mathrm{C}$ stretching region of TDP were detected for the pure TDP at melting state and all its blends, indicating that TDP in the blends is in the amorphous state. The peak centered at wavenumber $1724 \mathrm{~cm}^{-1}$ corresponding to the 


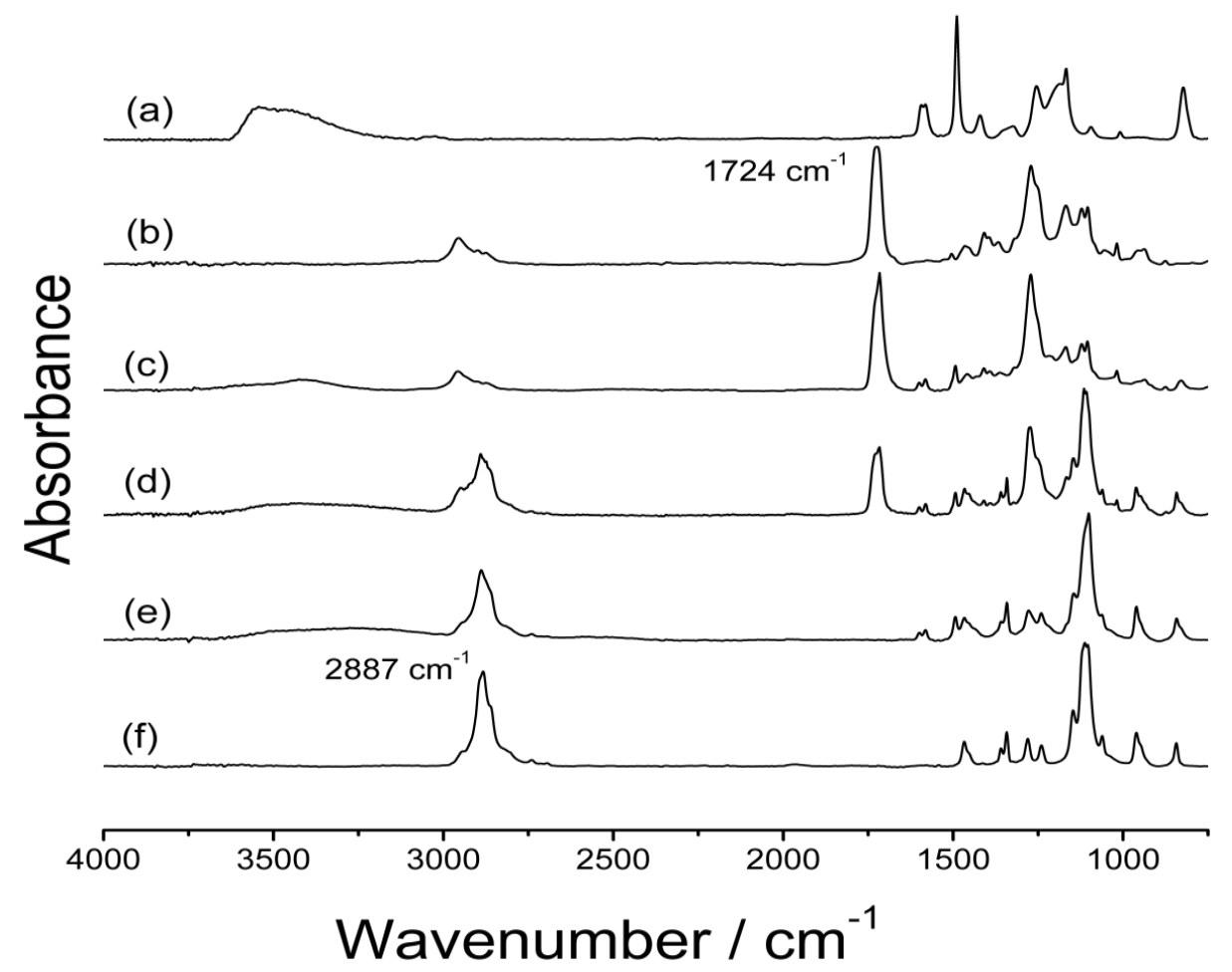

Fig. 5. FT-IR spectra of (a) pure TDP at $160 \circ \mathrm{C}$, and (b) pure P(BA-co-BT), (c) 92/8 (wt \% / wt \%) P(BA-co-BT)/TDP binary blend (d) 46/46/8 (wt \%/wt \%/wt \%) P(BA-coBT)/PEO/TDP ternary blend (e) 92/8 (wt \%/wt \%) PEO/TDP binary blend, (f) pure PEO observed at room temperature.

carbonyl vibration region of $\mathrm{P}(\mathrm{BA}-\mathrm{co}-\mathrm{BT})$ and that at $2887 \mathrm{~cm}^{-1}$ corresponding to the $\mathrm{C}-\mathrm{H}$ stretching region of PEO were detected for the pure $\mathrm{P}(\mathrm{BA}-\mathrm{co}-\mathrm{BT})$ and PEO films, respectively. Both of these characteristic peaks also appeared in the ternary 46/46/8 (wt $\% / w t \% / w t \%)$ blend film. There are some characteristic bands in the $\mathrm{C}-\mathrm{H}$ stretching region in the spectrum of pure $\mathrm{P}(\mathrm{BA}-\mathrm{CO}-\mathrm{BT})$, but they are very weak and broad. Therefore, the two peaks at $1724 \mathrm{~cm}^{-1}$ and $2887 \mathrm{~cm}^{-1}$ were used to analyze qualitatively the contents of the $\mathrm{P}(\mathrm{BA}-\mathrm{co}-\mathrm{BT})$ and $\mathrm{PEO}$ components, respectively, at the arbitrary position in the compositional gradient film.

The compositional change along the film thickness direction in the annealing process was investigated by FT-IR mapping measurements on the cross section of the resulted films after annealed for different times. In Figure 6, the intensities of the P(BA-co-BT) C=O, PEO C-H, and TDP $\mathrm{C}=\mathrm{C}$ absorption peaks are plotted against the position in the film thickness direction. It reveals that the interdiffusion process begins from the interface between the $\mathrm{P}$ (BA-co-BT)/TDP and PEO/TDP blends, and develops towards the two outer surfaces of the film. Finally, a well-structured continuous compositional gradient along the film thickness direction was formed after 12 hours annealing. 

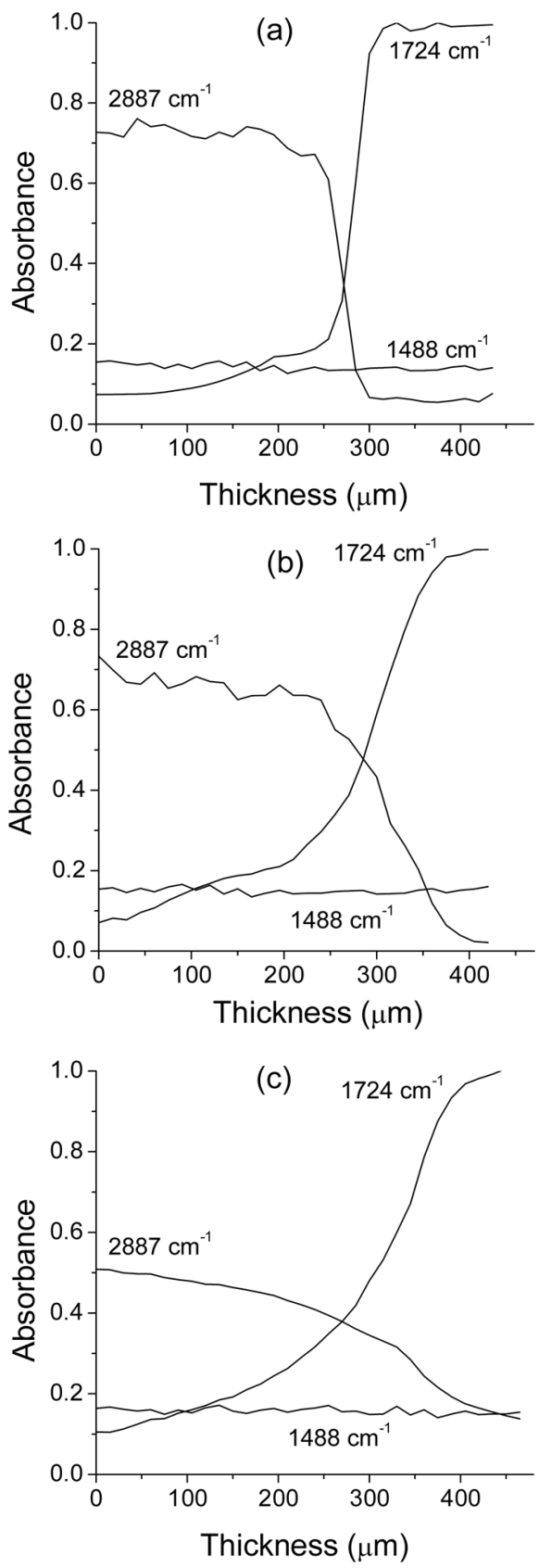

Fig. 6. Plots of the peak intensity of the $\mathrm{P}(\mathrm{BA}-\mathrm{co}-\mathrm{BT}) \mathrm{C}=\mathrm{O}, \mathrm{PEO} \mathrm{C}-\mathrm{H}$, and TDP $\mathrm{C}=\mathrm{C}$ absorptions along the thickness direction of the resulted films after annealed for (a) 4 hours, (b) 8 hours, and (c) 12 hours. 
The results of FT-IR mapping measurements on the cross section of the resulted film are shown in Figure 7. It is clearly seen that the peak intensity of $\mathrm{P}(\mathrm{BA}-\mathrm{co}-\mathrm{BT}) \mathrm{C}=\mathrm{O}$ vibration absorption at $1724 \mathrm{~cm}^{-1}$ continuously increases along the thickness direction while that of the PEO C-H stretching absorption at $2887 \mathrm{~cm}^{-1}$ decreases along the same direction. The weak bands centered at about $1600 \mathrm{~cm}^{-1}$ and $1488 \mathrm{~cm}^{-1}$ characteristic for TDP appear in all spectra and their peak intensities are almost constant over the whole thickness range, indicating that the TDP content is almost the same over the whole range in the thickness direction of the gradient film.

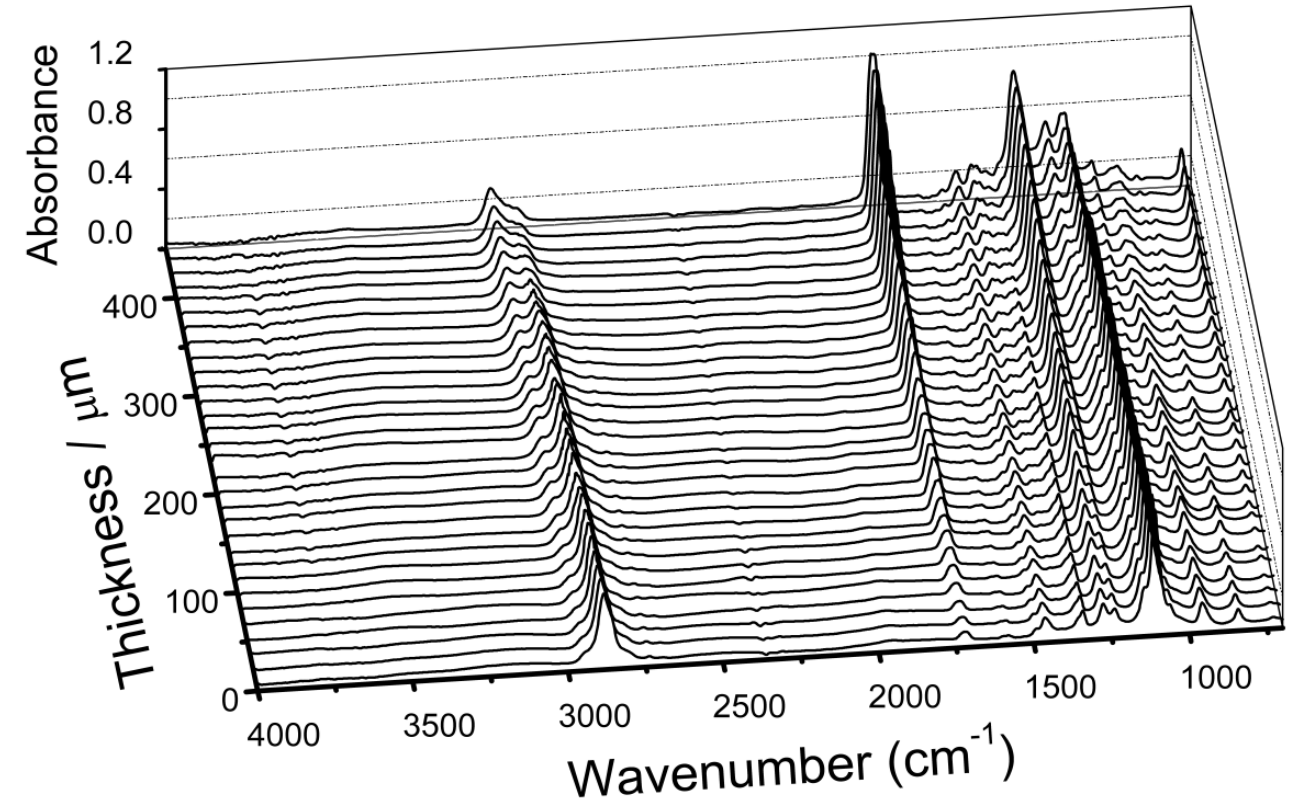

Fig. 7. Results of FT-IR mapping measurements on the cross section along the direction vertical to the sample surface.

The presence of a suitable content of TDP transformed the immiscible $\mathrm{P}(\mathrm{BA}-\mathrm{co}-\mathrm{BT}) / \mathrm{PEO}$ blend system into a miscible one through the intermolecular hydrogen bonding interactions, as experimentally demonstrated by DSC and FT-IR measurements (Hexig et al., 2004). In a miscible system, the favorable intermolecular interactions overwhelm the unfavorable intermolecular interactions and the free energy of the system decreases with mixing (Pines et al., 1972). As a result, the bilayered miscible polymer film shows a tendency towards homogeneous mixing. One more important factor is that the constant breaking and reforming of the hydrogen bond at a temperature above the glass transition (Coleman et al., 1991), especially at the high temperature used in this process provided the possibility and approach for the interdiffusion to occur. The optimal gradient structure can be obtained in the homogenizing process by controlling the interdiffusing time. The peak intensity of TDP $\mathrm{C}=\mathrm{C}$ absorption is almost constant over the whole thickness range at all the annealing time, indicating that the motion of TDP is an isotropic thermal motion. The mapping measurements also revealed almost the same results for the films regardless that the upper 
side in the annealing process was the PEO/TDP or the P(BA-co-BT)/TDP blend, indicating that the gravity has no effect on the gradation process.

\section{PAS-FTIR as a non-destructive, non-contact confirming method of compositional gradient structure}

Plasma technology can add functional groups to a surface of organic and inorganic materials at the molecular level, changing surface chemistries for increased bond strength, wettability, permeability, and activating and changing surfaces from hydrophobic to hydrophilic without affecting the bulk properties. The compositional gradient structure in hyaluronic acid (HA) and thermal responsible poly(N- isopropylacrylamide) (PIPAAm) blend film was self-organized during solvent evaporation process on the oxygen-plasma treated polystyrene dish (PTPSD), while on the non-treated polystyrene dish (NTPSD) nearly homogenous blend film was formed at ambient temperature. HA is a naturally occurring linear polysaccharide widely distributed in body as components of the extracellular matrix (ECM) of connective tissues, and HA-based biomaterials have been recently utilized for a variety of clinical application and tissue engineering of skin, cartilage tissue, and bone based upon its specific properties, excellent biocompatibility and bioactivity (Kano et al., 1997, Zacchi et al., 1998, Aigner et al., 1998, Solchaga et al., 1999). PIPAAm is a synthetic polymer which has a sharp and reversible phase transition at $\sim 32{ }^{\circ} \mathrm{C}$ and applicable in tissue engineering fields as a functional hydrogel and a cell sheet (Park et al., 2002, Yoshida et al., 1995, Yamada et al., 1990, 1993).

\subsection{Experiments}

\subsubsection{Plasma-treatment of polystyrene dish}

The plasma treatment was performed with a SWP-101EX (NISSIN Co, Ltd. Japan), using low-pressure region output power of the microwave oscillator at 2.0KW. Polystyrene dishes were set on the sample stage which was $15 \mathrm{~cm}$ below the reactor. The oxygen discharge was utilized and the oxygen was filled at a rate of $500 \mathrm{cc} / \mathrm{min}$ and a pressure of $70 \mathrm{~Pa}$. Plasma irradiation was performed for 15 seconds.

\subsubsection{Film preparation}

$1 \%$ HA solution was prepared by dissolving powder HA (weight average molecular weight 1680.000 by GPC, Life Core Biomedical Inc) in distilled water with stirring for 24 hours. $1 \%$ PIPAAM solution was prepared by diluting 15\% PIPAAM (weight average molecular weight 220.000 by GPC, Kohjin Co. Ltd) aqueous solution by distilled water with stirring for 24 hours. After then 1\% HA and 1\% PIPAAm solutions were mixed together at the same weight ratios and stirred further for 24 hours before casting on the PTPSD and NTPSD at ambient and vacuum conditions, respectively. All resulted sample films were heated at 80 ${ }^{\circ} \mathrm{C}$ under vacuum condition for 5 hours before characterization.

\subsubsection{PAS-FTIR spectroscopy measurements}

PAS-FTIR spectroscopy measurements were carried out on the JIR-SPX200 FT-IR spectrometer (JEOL Co. Ltd. Japan) equipped with a MTEC 300 photoacoustic cell (MTEC 
photoacoustic Ames USA). Prior to the start of penetration experiment the cell was purged with helium for 30 seconds.

\subsection{Results}

The step-scan PAS-FTIR is a non-destructive, non-contact method with controllable sampling depth and need little or no sample preparation. Figure 8 shows the results of PASFTIR spectroscopy measurements on the films cast on NTPSD and PTPSD in vacuum condition. PAS-FTIR spectra of increasing shallow-sampling depth corresponding to different mirror velocities of 1.0, 2.0 and $5.0 \mathrm{~mm} / \mathrm{s}$ indicate that the fractions of $\mathrm{HA}$ and

a

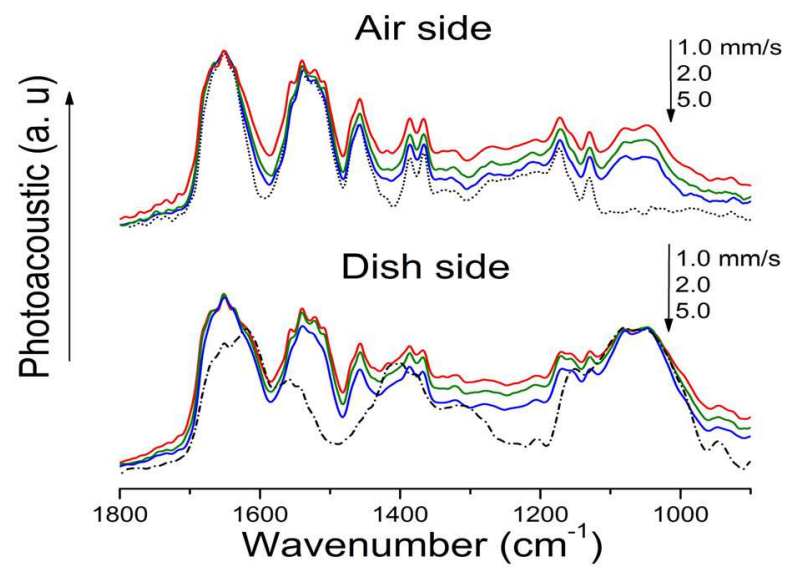

b

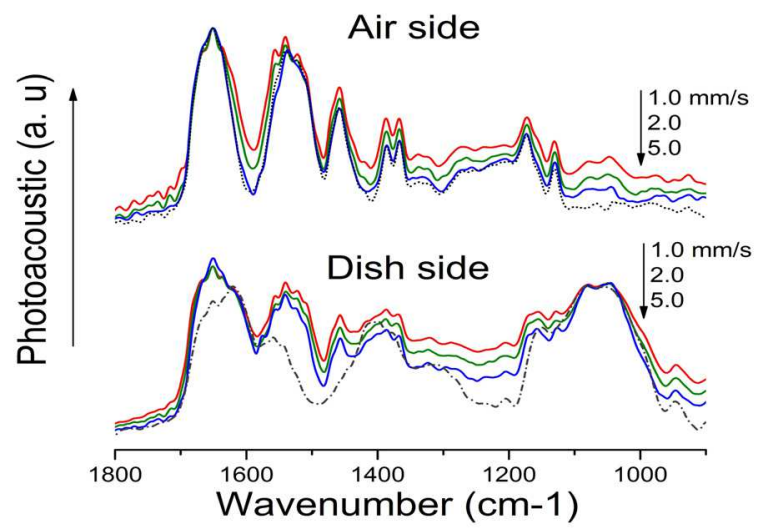

Fig. 8. Results of PAS-FTIR spectroscopy measurements on the films cast on NTPSD and PTPSD in vacuum condition. 
PIPAAm gradually change from the surfaces to the inside of the film for both films cast on NTPSD and PTPSD. For the film cast on PTPSD in vacuum condition, more significant compositional difference was observed between the dish side and the air side than the film cast on NTPSD in vacuum. In combination with XPS and EDX mapping measurements on the films cast on NTPSD and PTPSD at ambient and vacuum conditions, respectively, it was revealed that both the oxidized hydrophilic surface and evaporation rate of water molecules contribute to the formation of an ideal gradient structure in the HA/PIPAAm blend system (Hexig et al., 2010).

\section{Conclusions}

Developing a methodology for characterizing the gradient structure is with the same importance as developing a method to generate the gradient structure. Utilizing ATR-FTIR spectroscopy, we can confirm the compositional difference between the two surfaces of the compositional gradient materials, while FT-IR mapping measurements can give a information of the compositional change on the cross section. The step-scan PAS-FTIR is a non-destructive, non-contact method reveals the compositional difference corresponding to the varying sampling depth. Thus, with a reasonable combination of these FT-IR spectroscopy measurements, we can characterized and confirm the compositional gradient of FGMs satisfactorily.

\section{References}

[1] Bruck, H. A., Evans, J. J. \& Peterson, M. L.. Exp. Mech. 42. 361-371 (2002).

[2] Hench, L. L. \& Polak, J. M. 295, 1014-1017 (2002).

[3] Akaike, T. 35- 67 (Corona, Tokyo, Japan, 2005).

[4] Amada, S., Ichikawa, Y., Munnekta, T., Munekata, T., Nagase, Y. \& Shimizu, H. Composites part B, 28B, 13-20 (1997).

[5] Suresh, S. Science 292. 2447- 2451 (2001).

[6] Suganuma, K., Okamoto, T., Shimada, M. \& Koizumi, M. J. Amer. Ceram. Soc. 66, c117c118 (1983).

[7] Ishikawa, T. et al. Nature 416, 64-67(2002).

[8] Czubarow, P. \& Seyferth, D. J. Mater. Sci. 32, 2121-2130 (1997).

[9] Kawasaki, A. and Watanabe R., J. Japan Inst. Merals, 1987. 51. 525.

[10] Ming Dao, Pei Gu, Akhilesh Maewal, and R. J. Asaro. Acta mater. 1997. 45. 3265

[11] G. Zuccarello, D. Scribner, R. Sands, and L. J. Buckley, Advanced Materials. 2002, 14, 1261.

[12] M. Kryszewski, Polymers for Advanced Technologies. 1998, 9, 244.

[13] D. Ma, J. M. Lupton, R. Beavington, P.L. Burn, I. D. Samuel, Adv, Funct, Mater. 2002, 12, 507.

[14] Y. Aragi, M. Shimada, A. Uede, Macromol. Chem. Phys. 1996, 197, 2017.

[15] Y. Kano, S. Akiyama, H. Sano, Polym. J. 1997, 29, 158.

[16] X. Xie, T. Xiao, Z. Zhang, A. Tanioka, J. Colloid and Interface Sci. 1998, 206, 189.

[17] B. Hexig, H. Alata, N. Asakawa, Y. Inoue, Sci. B Polym. Phys. 2005, 43, 368.

[18] B. Hexig, H. Alata, Y. Inoue, J. Polym. Sci. B Polym. Phys. 2005, 43, 3069.

[19] B. Hexig, H. Alata, N. Asakawa, Y. Inoue, Adv. Funct. Mater. 2005, 15, 1630. 
[20] B. Hexig, K. Isama, Y. Haishima, T. Tsuchiya, Y. Inoue, T. Akaike, Journal of Biomaterials Science 2010, 21, 1957.

[21] C. Allen, D. Maysinger, A. Eisenberg, Colloids Surf. B. 1999, 16, 3.

[22] E. E. Dormidontova, Macromolecules. 2002, 35, 987.

[23] T. Miyoshi, K. Takegoshi, K. Hikichi, Polymer. 1996, 37, 11-18.

[24] H-L. Chen, S-F. Wang, Polymer. 2000, 41, 5157.

[25] Y-Ho. Na, Y, He. N. Asakawa, N. Yoshie, Y. Inoue, Macromolecules, 2002, 35, 727-735.

[26] Y. He, N. Asakawa, Y. Inoue, Polym Int. 2000, 49, 609.

[27] T. Uesaka, K. Nakane, S. Maeda T. Ogihara, N. Ogata, polymer, 2000, 41, 8449.

[28] Z. B. Qiu, T. Ikehara, T. Nishi, Polymer. 2003, 44, 2799.

[29] M. M. Coleman, J. F. Graf, P. C. Painter, Specific Interaction and the Miscibility of Polymer Blends, Technomic Publishing: Lancaster, PA, 1991.

[30] B.Hexig, N. Asakawa, Y.Inoue, J.Polym.Sci. Part B, 2004, 42, 2971.

[31] A. Pines, M. G. Gibby, and J. S. Waugh J. Chem. Phys. 1972. 56. 1776.

[32] Kano, Y., Akiyama, S., Sano, H. \& Yui, H. Polym. J. 29. 158-164 (1997).

[33] Zacchi, V. et al. J. Biomed. Mater. Res. 40, 187-194 (1998).

[34] Aigner, J. et al. J. Biomed. Mater. Res. 42, 172-181 (1998).

[35] Solchaga, L. A., Dennis, J. E., Goldberg, V. M. \& Caplan, A. I. J. Orthop. Res. 17, 205-213 (1999).

[36] Park, J. U. \& Tsuchiya, T. J. Biomed. Mater. Res. 60, 541-547 (2002).

[37] Yoshida, R. et al. Nature 374, 240-242 (1995).

[38] Yamada, N. et al. Thermo-responsive polymeric surface; Makromol Chem Rapid Commun. 11, 571-576 (1990). J. Biomed. Mater. Res. 27, 1243-1251 (1993). 


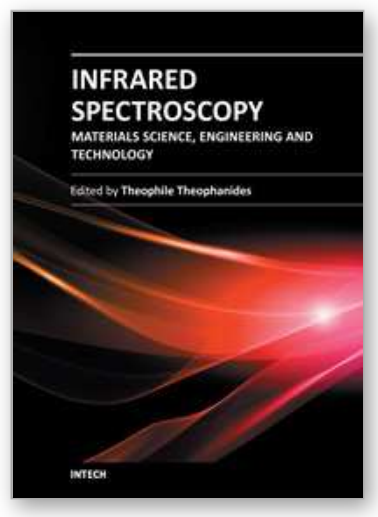

\author{
Infrared Spectroscopy - Materials Science, Engineering and \\ Technology \\ Edited by Prof. Theophanides Theophile
}

ISBN 978-953-51-0537-4

Hard cover, 510 pages

Publisher InTech

Published online 25, April, 2012

Published in print edition April, 2012

The present book is a definitive review in the field of Infrared (IR) and Near Infrared (NIR) Spectroscopies, which are powerful, non invasive imaging techniques. This book brings together multidisciplinary chapters written by leading authorities in the area. The book provides a thorough overview of progress in the field of applications of IR and NIR spectroscopy in Materials Science, Engineering and Technology. Through a presentation of diverse applications, this book aims at bridging various disciplines and provides a platform for collaborations among scientists.

\title{
How to reference
}

In order to correctly reference this scholarly work, feel free to copy and paste the following:

Alata Hexig and Bayar Hexig (2012). Characterization of Compositional Gradient Structure of Polymeric Materials by FTIR Technology, Infrared Spectroscopy - Materials Science, Engineering and Technology, Prof. Theophanides Theophile (Ed.), ISBN: 978-953-51-0537-4, InTech, Available from:

http://www.intechopen.com/books/infrared-spectroscopy-materials-science-engineering-and-

technology/characterization-of-compositional-gradient-structure-of-polymeric-materials-by-ft-ir-technology

\section{INTECH}

open science | open minds

\section{InTech Europe}

University Campus STeP Ri

Slavka Krautzeka 83/A

51000 Rijeka, Croatia

Phone: +385 (51) 770447

Fax: +385 (51) 686166

www.intechopen.com

\section{InTech China}

Unit 405, Office Block, Hotel Equatorial Shanghai

No.65, Yan An Road (West), Shanghai, 200040, China

中国上海市延安西路65号上海国际贵都大饭店办公楼405单元

Phone: +86-21-62489820

Fax: +86-21-62489821 
(C) 2012 The Author(s). Licensee IntechOpen. This is an open access article distributed under the terms of the Creative Commons Attribution 3.0 License, which permits unrestricted use, distribution, and reproduction in any medium, provided the original work is properly cited. 